www.jmscr.igmpublication.org

Impact Factor 5.84

Index Copernicus Value: 83.27

ISSN (e)-2347-176x ISSN (p) 2455-0450

crossref DOI: _https://dx.doi.org/10.18535/jmscr/v5i3.128

Journal Of Medical Science And Clinical Research

\title{
Normal Vs Low Serum Level Vitamin D in Patient with Symptomatic Early RA Disease Activity
}

Authors

\author{
Sami Abdulhakim ${ }^{1}$, Salama Saad Abdullatif ${ }^{2}$, Gamal Abobar $^{3}$, Maay Weza ${ }^{3}$ \\ ${ }^{1}$ Rheumatol and Rehabilitation' Faculty of Medicine, ${ }^{2}$ Clinical Pathology \\ ${ }^{3} \mathrm{Al}$ Azhar University Radiology Dept, ${ }^{3} \mathrm{MSUS}$ \\ Email: Sami_1410@yahoo.co.uk
}

\begin{abstract}
The aim of this study to show the relation of low vs normal serum vitamin D 25(OH)D (vit D) level in the patient with early onset RA to disease activity.

METHODS: 92 RA Patients (72 female and 20 male) with recent-onset $R A$ were assessed clinically and radiographically of both hand $x$-ray and MSUS assessment, laboratory assessment (RF, anti-CCP, CBC, ESR, and chemistry), disease activity measurement (disease activity HAQ,VAS and DAS-28 score), all data were obtained at the beginning of first three months the disease. Patients are classified into two groups according to the level of vitamin D (normal or low). All cases of hyperparathyroidism, hypothyroidism and the patients who are already received vitamin $D$ or biological therapy are excluded in the study.

RESULTS: 92 RA patients (72 females, 20 males) with early onset RA disease less than 6 six months duration. Healthy group age was $38.05 \pm 3.49$ with normal vitamin D serum level 32.13 \pm 13.07 . Total patient showed mild decrease in Vit. D than normal value, but there is highly significant differences between DAS28, HAQ, VAS, MSUS assessment in patient low vs normal Vit. D and inverse relation with disease activity and a significant correlation with disease activity HAQ, and VAS score $p<0.05$.

CONCLUSIONS: There is statistical significant relation with disease activity assessment difference between low vs normal 25(OH)D serum levels in RA early disease activity, So large number of epidemiological studies needed for optimal 25(OH)D concentrations with serial assessment of disease activity in RA patients.
\end{abstract}

KEYWORD: RA, Vit D low vs normal value, MSUS.

\section{Introduction}

Rheumatoid arthritis (RA) is a highly heterogeneous disease with respect to the joint destruction. The reasons underlying this heterogeneity are unknown. RA activity characterized by synovial tissue hypertrophy and pannus formation that invades the cartilage, followed by bone destruction.

Early recognition of disease activity and its association with other comorbidities and possible radiographic changes suing MSUS or X-ray hand, presence or absence of ACPA and other parameter of disease activity measurement ${ }^{14}$.

Serum levels of vitamin D levels are found to be reduced in patients with rheumatoid arthritis (RA) and have been implicated in disease pathogenesis. Recently, a new vitamin D receptor transcriptional signature is identified in the synovial tissues from rats with mild and non-erosive arthritis, suggesting a vitamin D-mediated protective effect. 
Reduced serum levels of vitamin D and its metabolites were commonly seen in RA might increase the risk for cartilage destruction and bone erosions ${ }^{15}$.

Vitamin $\mathrm{D}$ has a modulatory effect on $\mathrm{B}$ lymphocytes and Ig production and indeed exerts a direct effects on $\mathrm{B}$ cell homeostasis. Vit D has a circannual rhythm and shows a negative correlation with clinical status of rheumatoid arthritis with greater radiographic evidence of disease progression at 12 months, possibly related to seasonally lower serum levels of vitamin $\mathrm{D}^{6}$. Epidemiological evidence indicates a significant association between vitamin D deficiency and an increased incidence of autoimmune diseases. The immune-regulatory properties, and potent immunomodulatory activity of the Vitamin D on dendritic cells, Th- 1 and Th-17 cells, and the B cells have been confirmed. Serum levels of vitamin $\mathrm{D}$ have been found to be significantly lower in patients with autoimmune diseases than in the healthy population. In addition, it was also found that lower levels of vitamin D were associated with higher disease activity in rheumatoid arthritis. ${ }^{6}$.

\section{Patients and Methods}

All the patients underwent baseline clinical examination at the beginning of her/his disease activity with HAQ assessment and VAS score were taken; at the baseline, we recorded demographic data of patient (age, weight, and height), duration of disease activity, onset, course, and response to treatment in the first six months of the disease.

The study was recorded the pain score measured with a visual analog scale (VAS), Health assessment questionnaire(HAQ), swollen joint count the 28 tender and, the 28-joint disease activity score (DAS28).

DAS 28 score below $<2.5$ is considered as remission, 2.6-3.1 was mild disease activity, 3.25.1 was moderate disease activity and $>5.1$ have high disease activity.
HAQ is a validated generic measure of physical function; the total score ranged from 0 to $3: 0-1=$ mild disability; $>1-2=$ moderate disability; and $>2-3=$ severe disability.

VAS for (Pain VAS 0-10) was interpreted in three ranges: $0-3.5=$ low level; $3.6-6.5=$ average; and $6.6-10=$ high level of pain sensation.

Lab assessment were done by same Lab area; Blood sample was collected, separated with centrifugation store below 20 degrees CBC, (ESR) erythrocyte sedimentation rate by Westergren method; rheumatoid factor was measured by nephlometry; anti-CCP anti-cyclic citrullinated peptide antibodies measured by ELISA Anti-CCP antibody serum value more than 20 serum level was considered as a positive value. Vitamin D serum level assessed by enzyme-linked immunosorbent assay with cut value 20 is considered as low value.

Ultrasonographic assessment of both wrist joints for detection of synovitis performed using a scanner with a multi frequency $12 \mathrm{~L}$ linear array transducer (General electric Systems; LOGIQU-E) in B mode and power Doppler. Wrist synovitis was assessed by dorsal longitudinal scan according to EULAR standards, synovitis defined as intraarticular hypoechoic lesion that is non displaceable and poorly compressible. Grading for synovitis in gray scale as normal, mild, moderate and sever. Power Doppler graded as: Grade 0: Absence of abnormal vessel dots, Grade 1, mild synovitis: Single vessel dots, Grade 2, moderate synovitis: Several vessel dots, partially confluent covering less than half the area of synovium, Grade 3, sever synovitis: Confluent vessel dots covering more than half the area of synovium. Effusion defined as intraarticular hypoechoic structure that is displaceable and compressible. Erosion defined as bone cortical break with step down abnormality that was confirmed in two perpendicular planes. ${ }^{17,8}$

Baseline hand PA view by same radiographs; the joints assessed were- bilateral thumb interphalangeal (IP) joints, PIP joints 2-5, MCP joints $1-5$, and wrists joints. Each wrist was considered a unit 
and its score was multiplied by 5 . Thus, the Larsen score ranged from 0 to 200. An erosion joint count (EJC) was made, defined as the number of joints with any evidence of cortical erosion out of 32 joints. All radiographs were read by the same observer. In this study, $87.5 \%$ of a patient has a juxta-articular osteopenia PA view when first time of the assessment, no erosion or joint space loss or deformity. $12.5 \%$ remaining showed juxta-articular osteopenia with mild erosion at the base of MCP or PIP joint one area only. Ethical committee approved the protocol and methods of the study.

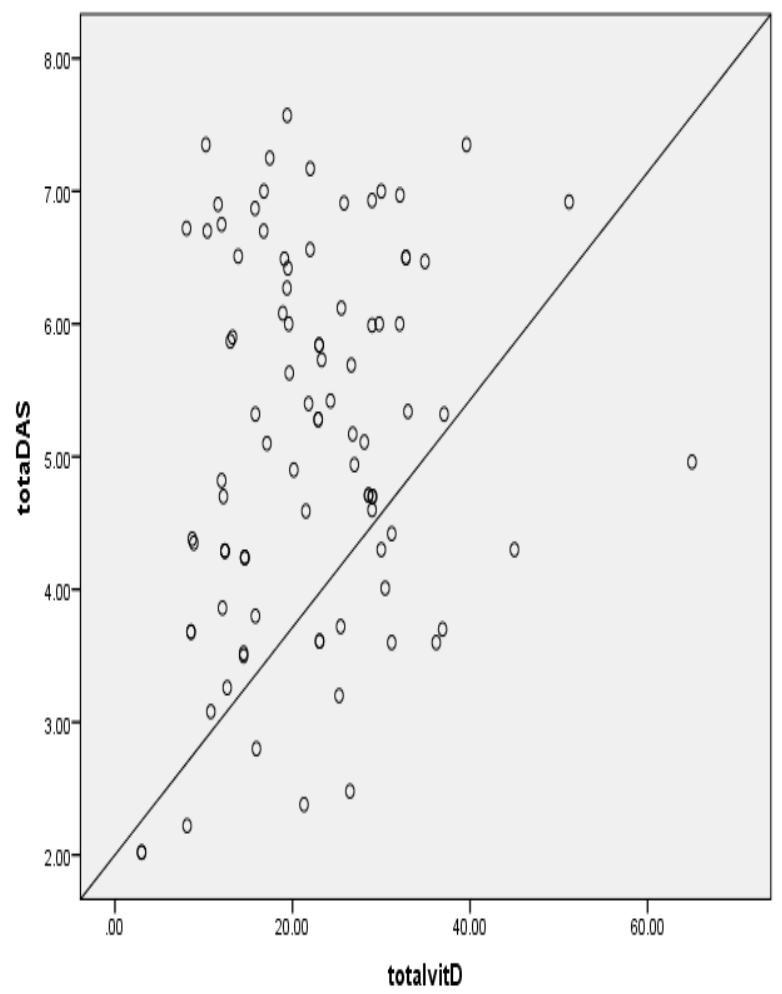

Inclusion Criteria: Patients was diagnosed according to EULAR criteria 2010, with symptoms of less than six months duration were included in this study visiting rheumatology outpatient clinic of a period from December 2012 to 2015. All Patients are treated with DMARDS with or without Prednisone for less than $10 \mathrm{mg} /$ day with a weekly dose of MTX 10-25 mg and HXQ200-400 mg.

Exclusion Criteria: All patients with increased parathyroid hormone levels, hypo-or hyperthyroidism, chronic kidney disease, inflammatory bowel disease or patient with intake of vitamin D in last three months or with intake of corticost- eroid of more than $10 \mathrm{mg}$ per day or any patient was treated with the biological therapy before assessment are excluded from this study.

Statistical Analysis: Demographic data with mean and SD and frequency are calculated in this study. The data are collected and analysis was done SPSS ver21. Data was assessed for normality distribution for low and normal vitamin $\mathrm{D}$ in relation to (by Kolmogorov-Smirnova 0.230, 0.111 or high $0.217,0.202$ ), to DAS28 score showed non-significant relation $\mathrm{P}>0.05$.

MSUS assessment of both wrist (synovial hypertrophy, effusion, erosion and positive or negative power Doppler sign were recorded) the analysis of variables used the $\chi 2$ test or Pearson's test, and continuous variables were assessed with Student's t-test. The significant value was $\mathrm{P}<0.05$. Vitamin D (low vs normal value does it show any relation to Anti-CCP interaction and MSUS assessment vs Disease activity). The control group was recruited from the same family of the patient group brother, sister to minimize an effect of lifestyle and nutritional state for vitamin D and exclude health person with low Vit D). The following graph showed a distribution of cases vitamin $\mathrm{D}$ in relation to DAS score.

\section{Results}

In this study, 92 patients were enrolled initially; the baseline characteristics are shown in Table1 in form of Mean, SD, and P value. The mean age of the total study group was $38.05 \pm 3.39$, vitamin D was $39.60 \pm 21.08$ with the significant difference between male and female group $\mathrm{p}<0.05$; otherwise no significant differences $\mathrm{P}>0.05$. The controlled healthy group age was $35.5 \pm 3.09$ with normal vitamin D serum level was $36.53 \pm 14.07$. The weight of the study group was $81.38 \pm 14.46 \mathrm{~kg}$ and height was $160.13 \pm 6.52 \mathrm{~cm}$. Also, there is a highly significant difference between low vs high serum vitamin $\mathrm{D}$ level $\mathrm{t}=14.6 \mathrm{p}<0.001$. Overall assessment of the study group showed, age was $38.05 \pm 3.39$ years with duration of the disease was $3.36 \pm 0.86$ moths, and ACPA was 219.50 \pm 302.17 , RF was $53.43 \pm 40.40$, ESR was $38.67 \pm 23.91$, 
VAS score was $4.18 \pm 2.84$, DAS score was 5.08 \pm 1.44 , and HAQ score was $1.86 \pm 0.62 . \mathrm{RF}$ and ACPA showed a significant difference between both group in patient with High VS low vitamin D serum level $\mathrm{P}<0.05 \mathrm{t}=3.4$ and 3.2 respectively. Carpal tunnel syndrome was found in $31.80 \%$ of cases, $11.00 \%$ positive tinnel sign at the posterior tibial nerve tarsal tunnel and $57.20 \%$ of patient with showed no sign of entrapment neuropathy. As regard to neurological entrapment neuropathy in the patient with RA showed no significant relation between vit $\mathrm{D}$ and entrapment (carpal tunnel, tarsal tunnel), $\mathrm{P}>0.05$. Also, there is no a significant correlation between both group $\mathrm{r}=0.4$, $\mathrm{P}>0.05$.

The study group was classified into low vs normal value of vitamin $\mathrm{D}$, the results showed, ACPA, RF, VAS, DAS-28 score were significantly higher in the patient with low vitamin $\mathrm{D}$ level than patient with normal vitamin $\mathrm{D}$ level $\mathrm{P}<0.05$, while, HAQ score more significantly higher in study group than low vitamin D serum level $\mathrm{P}<0.05$. Otherwise, no significant difference was detected $\mathrm{P}>0.05$ Table 2 .

Table 1: Demographic data of all study group:

\begin{tabular}{|l|c|c|c|}
\hline Variable & Total Patient Group & Low Vitamin D & Normal Vitamin D \\
\hline Age & $38.05 \pm 3.39$ & $38.48 \pm 3.29$ & $37.91 \pm 3.69$ \\
\hline Duration/Month & $3.36 \pm 0.86$ & $3.28 \pm 0.82$ & $2.27 \pm 0.75$ \\
\hline ACPA & $219.50 \pm 302.17$ & $315.68 \pm 355.15^{*}$ & $143.32 \pm 197.26$ \\
\hline RF & $53.43 \pm 40.40$ & $81.66 \pm 110.46^{*}$ & $25.21 \pm 51.24$ \\
\hline ESR & $38.67 \pm 23.91$ & $35.50 \pm 26.93$ & $43.96 \pm 18.60$ \\
\hline VAS & $4.18 \pm 2.84$ & $5.79 \pm 2.71^{*}$ & $2.57 \pm 1.90$ \\
\hline DAS-28 & $5.08 \pm 1.44$ & $5.79 \pm 2.71^{*}$ & $2.57 \pm 1.90$ \\
\hline HAQ score & $1.86 \pm 0.62$ & $1.53 \pm 0.50$ & $2.18 \pm 0.85^{*}$ \\
\hline
\end{tabular}

Also, the patient of the study showed, polyarticular type of RA has an insidious onset in $54.4 \%$, and $44.4 \%$ has a subacute onset polyarthritis and 1.1 has a palindromic type of arthritis. The course of the disease process in this study showed $82.2 \%$ has a progressive course and $12.2 \%$ has an intermittent (remission and exacerbation of the disease activity) course and stationary course (low disease activity) in $5.6 \%$ of cases.

Also, the results of this study showed, insidious polyarticular onset is a significantly higher in normal than low vitamin $\mathrm{D}$ level $\mathrm{P}<0.05$. The subacute polyarticular onset of disease showed, a non-significantly increased in the patient with low vs normal vitamin D serum level. Also, $1.7 \%$ of patient with low vitamin D level palindromic type arthritis in the study group (table 2).

The RA activity has a progressive course, has a significantly higher in the patient with low than normal vitamin $\mathrm{D}$ level $\mathrm{P}<0.05$. While intermittent course is a significantly higher in normal vs low serum vitamin $\mathrm{D}$ level $\mathrm{P}<0.05$ (table 2).

Frequency of disease activity in the study group (Table 2):

\begin{tabular}{|l|c|c|c|c|c|c|c|}
\hline Variable & $\begin{array}{c}\text { \% Total } \\
\text { Patient } \\
\text { Group } \\
(\mathrm{n}=92)\end{array}$ & $\begin{array}{c}\text { \% Low } \\
\text { Vit. D } \\
(\mathrm{n}=61)\end{array}$ & $\begin{array}{c}\text { \% } \\
\text { Normal } \\
\text { Vit. D } \\
(\mathrm{n}=31)\end{array}$ & Duration/month & $\begin{array}{c}\text { \% Total Patient } \\
\text { Group (n= 92) }\end{array}$ & $\begin{array}{c}\text { \% Low } \\
\text { Vit. D } \\
(\mathrm{n}=61)\end{array}$ & $\begin{array}{c}\text { \% } \\
\text { Normal } \\
\text { Vit. D } \\
(\mathrm{n}=31)\end{array}$ \\
\hline Insidious & 54.4 & 53.3 & 60.9 & 1 & 0 & 0 & 0 \\
\hline Subacute & 44.4 & 45.0 & 39.1 & 2 & 18.9 & 21.7 & $87.0 *$ \\
\hline Palindromic & 1.1 & 1.7 & & 3 & 35.6 & $41.7 *$ & 4.3 \\
\hline Total & 100 & 100.0 & 100.0 & 4 & 41.1 & 33.3 & 4.3 \\
\hline Intermittent & 12.2 & 8.3 & $34.8 *$ & 5 & 4.4 & 3.3 & 4.3 \\
\hline Progressive & $82.2^{*}$ & $88.3 *$ & 60.9 & Total & 100.0 & 100.0 & 100.0 \\
\hline Steady & 5.6 & 3.3 & 4.3 & & & & \\
\hline Total & 100 & 100.0 & 100.0 & & & & \\
\hline
\end{tabular}


Frequency of disease activity in the study group (Table 3):

\begin{tabular}{|l|c|c|c|}
\hline Variable & $\begin{array}{c}\text { \% Total Patient } \\
\text { Group }(\mathrm{n}=92)\end{array}$ & $\begin{array}{c}\text { \%ow Vitamin D } \\
(\mathrm{n}=61)\end{array}$ & $\begin{array}{c}\text { \% Normal Vitamin } \\
\mathrm{D}(\mathrm{n}=31)\end{array}$ \\
\hline HAQ1 & 27.6 & $47.1^{*}$ & 8.1 \\
\hline 2 & 59.2 & 52.9 & $65.5^{*}$ \\
\hline 3 & 13.2 & 0 & $26.4^{*}$ \\
\hline TOTAL & 100 & 100 & 100 \\
\hline VAS No & 0 & 0 & 0 \\
\hline Mild & 21.8 & 19.1 & 16.3 \\
\hline Moderate & 33.8 & 34.1 & $49^{*}$ \\
\hline Sever & 44.4 & $46.8^{*}$ & 34.7 \\
\hline TOTAL & 100 & 100 & 100 \\
\hline DAS 28 Score Remission & 5.90 & 5.0 & 0 \\
\hline Mild & 2.40 & 3.3 & 8.0 \\
\hline Moderate & 40.00 & 38.3 & 47.8 \\
\hline Sever & 51.80 & 53.3 & 100.0 \\
\hline TOTAL & 100.0 & 100.0 & \\
\hline
\end{tabular}

HAQ assessment in the study group showed, $47.1 \%$ of the cases with low disability (low HAQ) in a patient with low vitamin $\mathrm{D}$ level, while, $65.5 \%$ of cases with normal vitamin $\mathrm{D}$ have a moderate disability and $26.4 \%$ in patient normal vitamin D level showed severe disability (table 3).HAQ score in the study group showed that the patient with low vitamin D level has a significantly higher mild disease disability $\mathrm{P}<0.05$. While patient has a significant higher of moderate and severe disability in a patient normal than low vitamin D level $\mathrm{P}<0.05$ (table 3). VAS score, and HAQ score comparison between the patients with low VS normal Vitamin D. There is a significant difference between both groups regarding the course and pattern of disease presentation and $\mathrm{P}<0.05$ (table 3 ).

VAS scale showed that a patient with normal vitamin $\mathrm{D}$ level is a significantly higher than patient with low vitamin D level $\mathrm{P}<0.05$.Percentage of patient with severe pain not significantly high than moderate pain score P>0.05 (table 3).

VAS Score of the study group in the patient with low vs normal vitamin $D$ level showed a significant correlation between both groups regarding the mild, moderate ad sever pain $\mathrm{p}<0.05$; but no significant correlation regarding moderate to severe pain $\mathrm{P}>0.05$. Also, a nonsignificant difference between both groups regarding DAS score i.e. both group nearly equal disease activity $\mathrm{t}=0.5$ with $\mathrm{P}>0.05$ (table 3 ).

HAQ score showed a significant higher HAQ score assessment regarding disability in the patient with low vs normal vitamin $\mathrm{D}$ serum level $\mathrm{p}<0.05$.Also, vitamin D and HAQ score showed a highly significant relation between vitamin $\mathrm{D}$ and HAQ score $\mathrm{P}<0.05$. But, there is no significant correlation between HAQ score and vitamin D $\mathrm{r}=0.09, \mathrm{P}>0.05$.

Also, DAS 28 score in patient with low vs normal vitamin $D$ serum level showed a non-significant differences between both groups $\mathrm{P}>0.05$, and showed also, a non-significant correlation between both group $r=0.1$.

Overall MSUS assessment in the study group most patient has a mild effusion $82.2 \%$ with mild effusion vs $17.8 \%$ showed moderate effusion. Synovitis was detected early in the study group $68.9 \%$ of mild synovitis and $26.7 \%$ showed moderate synovitis with only $4.4 \%$ of cases showed sever form of synovitis. Erosion was detected early better than X-ray assessment in this group $(87.5 \%$ of patient have juxta-articular osteopenia vs $12.5 \%$ has an erosion) while MSUS showed 76.8 moderate 32.2 moderate erosion and PWD activity 68.9 vs $31.1 \%$ of cases has a PWD activity in the study group. 
MSUS in the study group (Table 4):

\begin{tabular}{|l|c|c|c|}
\hline $\begin{array}{l}\text { Variable } \\
\text { MSUS }\end{array}$ & \% Total Patient Group (n= 92) & $\begin{array}{c}\text { \% Low Vit. D } \\
(\mathrm{n}=61)\end{array}$ & $\begin{array}{c}\text { \% Normal Vit. D } \\
(\mathrm{n}=31)\end{array}$ \\
\hline EFFUSION & & & 0 \\
\hline NO & 0 & 0 & 30.4 \\
\hline MILD & 82.2 & $86.7^{*}$ & $65.2^{*}$ \\
\hline MODERATE & 17.8 & 13.3 & 4.3 \\
\hline SEVER & 0 & 0 & $\mathbf{1 0 0}$ \\
\hline SYNOVITIS & $\mathbf{1 0 0}$ & $\mathbf{1 0 0}$ & 0 \\
\hline NO & 0 & $65.0^{*}$ & 34.8 \\
\hline MILD & 68.9 & 33.3 & $60.9^{*}$ \\
\hline MODERATE & 26.7 & 1.7 & 4.3 \\
\hline SEVER & 4.4 & $\mathbf{1 0 0}$ & $\mathbf{1 0 0}$ \\
\hline EROSION & $\mathbf{1 0 0}$ & 0 & 0 \\
\hline NO & 0 & 68.3 & $87.0^{*}$ \\
\hline MILD & 67.8 & 31.7 & 0 \\
\hline MODERATE & 32.2 & 0 & 0 \\
\hline SEVER & 0 & $\mathbf{1 0 0}$ & 0 \\
\hline PWD & $\mathbf{1 0 0}$ & 0 & $69.6^{*}$ \\
\hline NO & 0 & 65.0 & 30.4 \\
\hline MILD & 68.9 & 35.0 & 0 \\
\hline MODERATE & 31.1 & 0 & $\mathbf{1 0 0}$ \\
\hline SEVER & 0 & $\mathbf{1 0 0}$ & \\
\hline Total & $\mathbf{1 0 0}$ & & \\
\hline
\end{tabular}

MSUS assessment in the study group showed mild effusion more with the patient who has low vitamin D $86.7 \%$, While, moderate effusion more common with patient normal vitamin D $65.2 \%$. Also, the patient with low vitamin D level showed mild synovitis while $60.9 \%$ of patient with moderate synovitis showed normal vitamin D level. Erosion also more in a patient with normal vitamin D $87 \%$ of the case. PWD is more in patient with normal vitamin D 69.6\% (Table 4).

Also, there is no a significant relation between total vitamin D serum level and MSUS assessment (synovitis, effusion, PWD, and erosion) $\mathrm{P}>0.05$.Also, MSUS assessment in both group (low vs high vitamin D) showed, no significant difference between both group $\mathrm{P}>0.05$ (effusion $\mathrm{x} 20.5$, synovitis $\mathrm{X} 2=1.2$ PWD X2 $=1.8$, Erosion $\mathrm{X} 2=0.28$ ) respectively.

While follow-up of the patient during the study showed $53.00 \%$ gradually increased symptoms and $45.60 \%$ improved after medication and $1.40 \%$ was a stationary course (no improvement).

Also in patients with normal serum levels of vitamin $\mathrm{D}$, there is $28.6 \%$ swan neck deformity, $47.6 \%$ boutonniere deformity and $23.8 \%$ with ulnar deviation; while in patients with low serum levels of vitamin D, $81.0 \%$ of patients have Zshaped deformity, $7.1 \%$ have ulnar deviation, $4.8 \%$ are with swan neck deformity and $7.1 \%$ with boutonniere deformity .

Neurological assessment of study group there was non-significant differences $66.7 \%$ vs. $61.9 \%$ associated with carpal tunnel syndrome, $28.6 \%$ vs. $23.8 \%$ tarsal tunnel syndrome and $4.8 \%$ vs. $14.3 \%$ double crush injury in patients have normal vs. low-level vitamin $\mathrm{D}$ respectively $\mathrm{P}>0.05$. Most of the patient presented with $52.4 \%$ vs. $42.9 \%$ generalized body ache in the patient with low vs. normal vitamin D level; associated clinical presentation in both group.

\section{Discussion}

RA is an inflammatory disease characterized by flares and remissions, flares being characterized by pain, swelling and tenderness and limited ROM in affected joints. Vitamin D is known to induce immunologic tolerance; thus, its deficiency may induce the development of autoimmune diseases, such as $\mathrm{RA}^{3}$.

Baykal et al (2012), recognized that vitamin D not only is important for calcium metabolism and maintenance of bone health but also plays an 
important role in reducing the risk of many chronic diseases including RA. Also, vit. D regulate the immune response by a variety of mechanisms, such as decreasing antigen presentation, inhibiting the proinflammatory $T$ helper type 1 profile and inducing regulatory $\mathrm{T}$ cells ${ }^{4}$.

Vitamin D deficiency is known to be associated with diffuse musculoskeletal pain and possible role of vitamin D in the pathogenesis, activity, and treatment of RA has been raised based on the results and observations of clinical and laboratory studies; Also, vitamin D intake has been linked to increased susceptibility and/or changes of disease activity in patients with $\mathrm{RA}^{9}$.

Sen and Ranganathan (2012), stated that vitamin $\mathrm{D}$ deficiency is highly prevalent in the general population including individuals with RAand there is a correlation between vitamin D levels and clinical manifestations and/or activity of the disease ${ }^{17}$.

Overall total vitamin $\mathrm{D}$ in this study, the resultshowed a significant decrease of Vit D than the control group, with a significant correlation with disease activity HAQ and VAS score but, no significant relation with a DAS28 score or MSUS assessment.

This means that most of the patient with RA have low serum $25(\mathrm{OH}) \mathrm{D}$ level, that may helpful to investigate the vitamin $\mathrm{D}$ levels in RA patients and the impact negative effect on disease process (pathogenesis) or poorly responding to treatment.

The study of Kim et al. 2012 supports the results of our study; supplementation of vitamin D has been proposed as a means to induce immune tolerance and thus prevent the development of autoimmune diseases.Recently, a combination of anti-rheumatic drugs with vitamin $\mathrm{D}$ has been suggested improvement in RA patients ${ }^{10}$.

Our results showed no significant relation between total vitamin D and DAS 28 score, similar results were found by Welsh et al(2011), in his study observed an inverse association between vitamin $\mathrm{D}$ levels and RA disease activity ${ }^{20}$.Also, Cutolo et al (2006), found an inverse relationship between vitamin D levels and disease activity in $\mathrm{RA}^{7}$.

The results of Craig et al. 2010; found that there is no relationship between vitamin $\mathrm{D}$ deficiency and disease activity in $\mathrm{RA}^{5}$; which agree with our results, regarding VAS and HAQ score and MSUS assessment but not with DAS 28 score.

Attar (2012), in his study found similar to our results; patients with high disease activity had the lowest 25(OH)D levels $(18.25 \pm /-8.3 \mathrm{nmol} / \mathrm{L})$ compared with patients with moderate $(35.13 \pm /$ $15.2 \mathrm{nmol} / \mathrm{L})$ and low $(38.05 \pm /-7.3 \mathrm{nmol} / \mathrm{L})$ disease activity $(\mathrm{p}<0.001)$. Serum $25(\mathrm{OH}) \mathrm{D}$ was negatively correlated with DAS28, which was statistically significant $(\mathrm{r}=-0.42, \mathrm{p}<0.001)$. However, significantly lower $25(\mathrm{OH}) \mathrm{D}$ values were found in patients who are poorly responding to treatment, and not in a state of disease remission ${ }^{2}$.

Our results showed that, the vitamin D deficiency has been linked to diffuse musculoskeletal pain, HAQ, VAS score also there is correlation study between disease activity and low vitamin $\mathrm{D}$ level. Andjelkovic et al (1999), explained our results in his study, showed a clinical improvement was strongly correlated with high dose oral alfacalcidol therapy showed a positive effect on disease activity in $89 \%$ of the patients (with $46 \%$ has a complete remission and $44 \%$ with a satisfactory effect) ${ }^{1}$. Only two patients $(11 \%)$ showed no improvement, but no new symptoms occurred. Alfacalcidol could therefore possibly be used as an adjunct therapy with DMARDs in patients with rheumatoid arthritis ${ }^{1}$.

Kostoglou et al (2012)stated that vitamin D deficiency has been implicated in the pathogenesis of autoimmune diseases and has been found to be associated with RA disease activity; may be linked to disease severity and diffuse musculoskeletal pain in RA; these results have therapeutic implications ${ }^{11}$.

The study agrees with opinion of Patel et al (2007), who mentioned in his study, RA patient should be scanned low for vit. D deficiency ${ }^{16}$. But, our result about disease activity and disability 
with vitamin D among study group were taken early in disease course. So, recommended to assay vit. D in patientsespecially who not satisfy good clinical remission or poor response to medication or have high DAS score; Also, during remissionor exacerbation should be assessed ${ }^{16}$.

The result in this study can be explained by Souberbielle et al (2010), in his published study, twenty-five experts from various clinical disciplines, a target level of at least 30 to 40 $\mathrm{ng} / \mathrm{mL}$ of 25 -hydroxyvitamin D (25(OH)D) serum level was recommended in adult patients with autoimmune disease or at risk for fractures, falls, cancer, and cardiovascular disease ${ }^{18}$.

Merlin et al (2004), stated that, the geometric mean $25(\mathrm{OH}) \mathrm{D}$ concentration was slightly lower in the patients compared with control group but is not showed a statistically significant differences in patients who develop RA which agree with our results. Also, she suggests that vitamin $\mathrm{D}$ does not play an important role in the pathogenesis of RA $^{14}$.

Limitation of this study is a small number of patients, no serial follow up assessment of vitamin D serum level, no comparison before and after study, also, cut off the value of vitamin D in this study was $20 \mathrm{ng} / \mathrm{dl}$ serum level. Circannual rhythm of vitamin was not assessed. Also, it should be conducted as large randomized controlled trials are necessary to establish the role of vitamin D in disease activity.

Finally,RA patient in this study have a nonsignificant lower vitamin D levels than control group and it has a positive correlation between disease activity measurement HAQ and VAS scoresand lab assessment especially ACPA, and ESR. There are highly significant difference between DAS-28 score or MSUS in patient withlow vs normal vitamin $\mathrm{D}$.

In conclusion, we found statistical significant relation with disease activity assessment difference between low vs normal 25(OH)D serum levels in RA early disease activity, solarge number of epidemiological studies needed for optimal 25(OH)D concentrations with serial assessment of disease activity in RA patients.

\section{References}

1. Andjelkovic Z, Vojinovic J, Pejnovic N, Popovic M, Dujic A, Mitrovic D, Pavlica L, Stefanovic D. Disease modifying and immunomodulatory effects of high dose 1 alpha $(\mathrm{OH})$ D3 in rheumatoid arthritis patients. Clin Exp Rheumatol. 1999 JulAug;17(4):453-6.

2. Attar SM.Vitamin D deficiency in rheumatoid arthritis. Prevalence and association with disease activity in Western Saudi Arabia. Saudi Med J. 2012 May;33(5):520-5.

3. Ifigenia Kostoglou-A, Panagiotis A, Aikaterini L, Ioannis R, and Christodoulos A: Vitamin D and rheumatoid arthritis Ther Adv Endocrinol Metab. 2012 December; 3(6): 181-187.

4. Baykal T, Senel K, Alp F, Erdal A, Ugur M.Is there an association between serum 25-hydroxyvitamin D concentrations and disease activity in rheumatoid arthritis? Bratisl Lek Listy. 2012;113(10):610-1.

5. Craig S., Yu F., Curtis J., Alarcón G., Conn D., Jonas B., et al. (2010) Vitamin D status and its associations with disease activity and severity in African Americans with recent-onset rheumatoid arthritis. J Rheumatol 37: 275-281. [PMC free article]

6. Cutolo M, Plebani M, Shoenfeld Y, Adorini L, Tincani A. Vitamin D endocrine system and the immune response in rheumatic diseases. Vitam Horm. 2011;86:327-51.

7. Cutolo M., Otsa K., Laas K., Yprus M., Lehtme R., Secchi M., et al. (2006) Circannual vitamin $\mathrm{d}$ serum levels and disease activity in rheumatoid arthritis: Northern versus Southern Europe. Clin Exp Rheumatol 24: 702-704. 
8. Ellegaard K, Torp-Pedersen S, Terslev L, Danneskiold-Samsoe B, Henriksen M, Bliddal H. Ultrasound Colour Doppler measurements in a single joint as measure of disease activity in patients with rheumatoid arthritis assessment of current validity. Rheumatology (Oxford) 2009; 48: 254-257.

9. Hirani V. (2012) Vitamin D status and pain: analysis from the Health Survey for England among English adults aged 65 years and over. Br J Nutr 107: 1080-1084.

10. Kim T., Choi S., Lee Y., Song G., Ji J. (2012) Combined therapeutic application of mTOR inhibitor and vitamin $\mathrm{D}(3)$ for inflammatory bone destruction of rheumatoid arthritis. Med Hypotheses 79: 757-760.

11. Kostoglou-Athanassiou I, Athanassiou P, Lyraki A, Raftakis I, Antoniadis C.Vitamin D and rheumatoid arthritis. Ther Adv Endocrinol Metab. 2012 Dec;3(6):181-7.

12. Kroot EJ, de Jong BA, van Leeuwen MA, Swinkels $\mathrm{H}$, van den Hoogen FH, van't Hof M, et al. The prognostic value of anticyclic citrullinated peptide antibody in patients with recentonset RA. Arthritis Rheum 2000;43:1831-5. 24.

13. Laragione T, Shah A, Gulko PS. The vitamin $\mathrm{D}$ receptor regulates rheumatoid arthritis synovial fibroblast invasion and morphology. Mol Med. 2012 Mar 27;18(1):194-200.

14. Merlin LA, Curtis J, Mikuls TR, Cerhan JR, Criswell LA, Saag KG. Vitamin D intake is inversely associated with rheumatoid arthritis: results from the Iowa Women's Health Study. Arthritis Rheum 2004;50:72-7.

15. Naredo E, Rodriguez M, Campos C, et al. Validity, reproducibility and responsiveeness of a twelve-joint simplified power Doppler ultrasonographic assessment of joint inflammation in rheumatoid arthritis. Arthritis Rheum 2008; 59:515-522.

16. Patel S, Farragher T, Berry J, Bunn D, Silman A, Symmons D: Association between serum vitamin $\mathrm{D}$ metabolite levels and disease activity in patients with early inflammatory polyarthritis. Arthritis Rheum 2007, 56:2143-2149

17. Sen D, Ranganathan P.Vitamin D in rheumatoid arthritis: panacea or placebo? Discov Med. 2012 Nov;14(78):311-9.

18. Souberbielle JC, Body JJ, Lappe JM, Plebani M, Shoenfeld Y, Wang TJ, et al. Vitamin D and musculoskeletal health, cardiovascular disease, autoimmunity, and cancer: Recommendations for clinical practice. Autoimmun Rev. 2010; 9:709715

19. Weiss S. (2011) Bacterial components plus vitamin $D$ : the ultimate solution to the asthma (autoimmune disease) epidemic? J Allergy Clin Immunol 127: 1128-1130. [PMC free article].

20. Welsh P., Peters M., Mc Innes I., Lems W., Lips P., McKellar G., et al. (2011) Vitamin D deficiency is common in patients with RA and linked to disease activity, but circulating levels are unaffected by TNF $\alpha$ blockade: results from a prospective cohort study. Ann Rheum Dis 70: $1165-1167$. 